\title{
RELATIVE PERMEABILITY CURVES AND WETTABILITY ALTERATIONS BY ALUMINA NANO PARTICLES FLOODING
}

\author{
Sayed Gomaa ${ }^{1,3}$, Adel Salem², and Mohamed Hassan ${ }^{3}$, \\ ${ }^{1}$ Mining and Pet. Eng. Dept., Faculty of Eng., AL-Azhar University \\ ${ }^{2}$ Pet. Eng. Dept., Faculty of Pet. \& Mining Eng., Suez University \\ ${ }^{3}$ The British University in Egypt (BUE)
}

\begin{abstract}
Nanotechnology was proposed as a new Enhanced Oil Recovery (EOR) technique for its great potential of increasing oil recovery either in secondary or tertiary recovery stage. Several types of nanoparticles have been used for different applications in the EOR. The recovery mechanisms of such improvement of these nano particles are still need more research to be interpreted. From these suspected parameter the rock wettability and relative permeability alteration. Moreover, these nanoparticles can be used in different concentration and different sizes in the EOR project. Consequently, it is very important to study the effect of these factors on the incremental oil recovery in order to create a successful EOR operations.
\end{abstract}

To achieve some of these concerns, a series of core flooding experiments was conducted to study the effect of Alumina nanofluid concentration in the displacing brine on the relative permeability curves, rock wettability and finally the ultimate recovery factor. During core flooding experiments, a sandstone core was used and all pertinent and required parameters are monitored and recorded. The relative permeability to oil and water were calculated, and the contact angle was measured to check the degree of the rock wettability while using this nanofluid as an additive to the displacing water.

The base run was performed using water to be used as a secondary recovery base run. The ultimate recovery factor by water flooding was found to be $60.38 \%$ of the OOIP. Then a flooding process using Alumina nanofluid, as an additive to the displacing water, has been conducted with five different concentrations $(3,5,7,10$, and $15 \mathrm{~g} / \mathrm{L})$. The ultimate recovery factor was calculated for all concentrations and has been found to be $74.38 \%, 75.09 \%$, $76.13 \%, 81.13 \%$, and $61.70 \%$ respectively. The drawback in the ultimate recovery of $15 \mathrm{~g} / \mathrm{L}$ run has been addressed and explained while the best concentration was the $10 \mathrm{~g} / \mathrm{L}$ Alumina nanofluid which led to a $20.75 \%$ oil recovery over that of water flooding.

The main recovery mechanisms are addressed and expected. The relative permeability curves for all of these experimental runs were measured at different nano alumina concentrations and compared to each other. The contact angle (as a mean to evaluate the wettability alteration) was measured in order to investigate the effect of this nano fluid on the rock wettability. It was found that those rocks became more water wet after using Alumina nanofluid. This work investigates and analyzes the new outcomes from implementing Alumina nanofluid for EOR. Ultimately, the knowledge gained from this work can be used as a guide to interpret and define the Nanofluids improvement mechanisms and help in drawing a road map for ongoing and future work. 
Keywords: Nanofluid, Alumina Nanoparticles, Wettability Alteration, Recovery Mechanisms, EOR.

\section{Introduction}

Nanotechnology is the construction of functional materials, devices, and systems by controlling matter at the nanoscale level (one-billionth meter), and the exploitation of their novel properties and phenomena that emerge at that scale [1]. Since there are many definitions for nanotechnology, the U.S. Environmental Protection Agency (EPA) uses the definition established by the National Nanotechnology Initiative (NNI). The NNI (NNI 2007) uses nanotechnology to comprise all of the following; (a) research and technology development at the atomic, molecular, or macromolecular levels, in the length scale of approximately 1-100 nanometer $(\mathrm{nm})$ range in any direction; (b) generating and using structures, devices, and systems that have novel properties and functions as a result of their small and/or intermediate size; and (c) ability to control or manipulate on the atomic scale.

Nanotechnology is thus the technology of the extremely small; one $\mathrm{nm}$ is defined as one billionth of a meter. In comparison, 1-nm is 50,000-100,000 of the diameter of a human hair; a sheet of paper is about 100,000 nanometers thick, and there are 25,400,000 nanometers in one inch [2].

The main reason that nanotechnology has been attracting attentions is the unique properties that objects show when they are formed at nano-scale. These differing characteristics that nano-scale materials show compared to their nature-existing form are useful in creating high quality products and dangerous when being in contact with body or spread in environment [3].

Various Nanofluids can be designed by the addition of nanoparticles to different base fluids. The stability or dispersion of nanoparticles in solutions relies on the functionality (or surface activity) of the nanoparticles. Nanotechnology in the petroleum industry has gained enormous interest in the recent years

There are so many research developments $[2,3,4]$ that immerges the nanotechnology in the different oil processes. Nanotechnology has proved that it is useful to all the oil industry phases from the exploration, the drilling, the well logging, the production to the EOR.

Alomair et al.(2014 )[5] studied the effect of different concentrations of Silicon oxide, Aluminum oxide, Nickel oxide and Titanium oxide on IFT and emulsion viscosity. The best recovery factor using heavy oil (17.45 API) was noticed by reducing the emulsion viscosity by $25 \%$ using Aluminum oxide nano-particles of 0.05 wt $\%$ concentration. The best RF was obtained by using a mixture of Silicon and Aluminum oxide of $0.05 \mathrm{wt} \%$ concentration.

Adel Salem - Hannora 2015-A) [6] studied the characteristics of nano-silica and alumina of different concentrations $(0.1,0.5$ and $1 \mathrm{wt} \%)$ and their effect on the recovery factor. The RF was ranging from $62 \%$ to $81 \%$ with highest RF recorded as $81 \%$ by using silica oxide nanoparticles of $0.5 \mathrm{wt} \%$ concentration. It was obvious that all alumina flooding tests recorded RF lower than water flooding. On the contrary, all silicon experiments recorded RF higher than water flooding.

Adel Salem - Hannora (2015-B) [7] studied the effect of particles size on the recovery factor. They prepared silica nano-particles with different sizes (140, 120, 100, $87 \mathrm{~nm})$ and flooding processes were accomplished by each size and compared with the water flooding base run which recorded $67 \%$ recovery factor. It was obvious that smaller sizes have greater effect on the recovery factor which can be enhanced by adding polymer. The recovery factor after nano-flooding ranged from $65 \%$ to $77 \%$ and increased to $80 \%$ by using polymer with nanosilicon. 


\section{Nano-particles propagation in porous medium}

Studying the propagation of those particles and the factors affecting it carries a potential to more effective use of them. Retention in porous medium is the controlling key in the propagation process which is believed to has several types and reasons, Bradford et al. (2003) [8] suggested that particles attachment in the rock surface is the reason of retention which varies due to surface roughness, heterogeneity in the charge, and colloid variability.

Another study made by Rodriguez et al. (2009) [9] suggested that different rock lithologies exhibit different rate of retention which reduced from $12 \%$ in Boise sandstone to around $2 \%$ in Texas cream. The effect of brine salinity on retention was also investigated by Caldelas et al. (2011) [10]. They found that higher salinity leads to higher retention, the same phenomenon was noticed by increasing temperature.

\section{Wettability}

The high importance of wettability in reservoir engineering application has drawn the attention of researchers to investigate novel methods to alter the wettability from oil wet to water wet or from water wet to highly water wet which lead to remarkable changes in the total recovery factor.

Wettability is crucial agent in reservoir engineering because it affects many other properties such as distribution of fluid, relative permeability and the flow behavior through the porous media. Torsater - Hendraningrat (2013) [11] investigated the effect of different nano particles concentration on the contact angle. They measured the contact angle of crude oil against brine /nanofluids at various concentrations on polished synthetic silica. Nanoparticles lower the contact angle of aqueous phase and consequently result in small hysteresis. The trend showed that the increased hydrophilic silica nanofluid concentration increased water wetness. The electrostatic repulsion force between the particles will be bigger when amount of nanoparticle is huge. Driven by the aqueous pressure of the bulk liquid, the nanofluid will spread along the solid surface and decreases the contact angle (Figure 1).

Nano-particles are believed to have a great potential in wettability alteration applications and many studies were accomplished to reveal this potential in enhanced oil recovery [11]. Silica nanoparticles $\mathrm{SiO}_{2}$ showed a remarkable effect on wettability of rock surfaces and cores treated with this type of particles showed very high recovery factors. In 2015, Li et al [12] studied experimentally the wettability alteration during nanofluid EOR process and they showed their effects on the ultimate oil recovery factor. They used Hydrophilic silica nanostructure particles and hydrophilic silica colloidal nanoparticles with different concentration in their experiments. They reached to a conclusion that nanofluid flooding can change core to be more water wet and the presence of the crude oil can affect the wettability alteration process by nanoparticles.

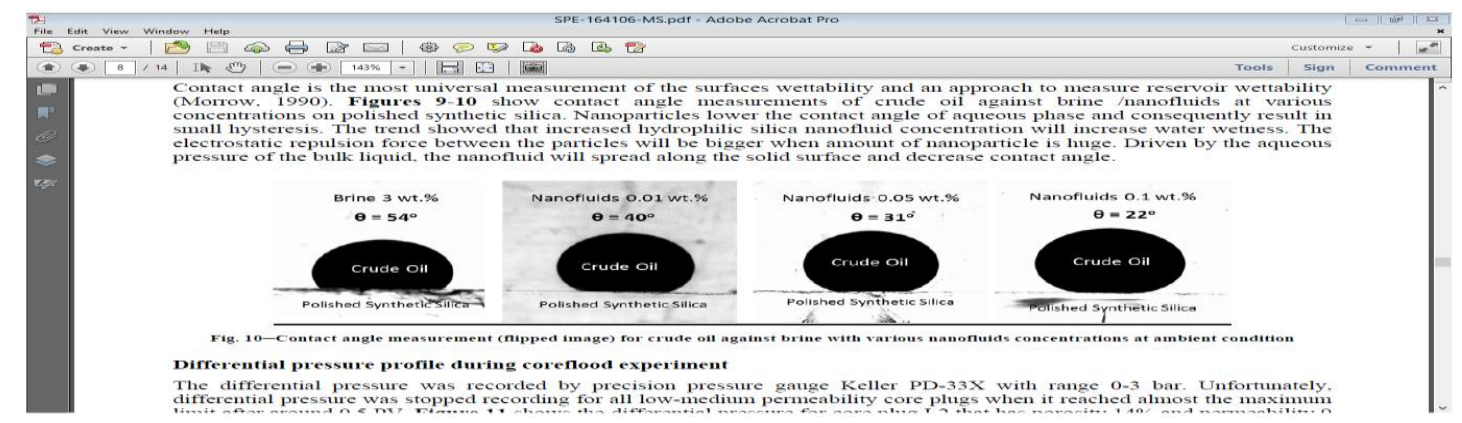

Fig. 1. Contact angle measurement (flipped image) for crude oil against brine with various nanofluids concentrations at ambient condition [11].

Sheshdeh [13] presented a review study of wettability alteration with nano particles applications. He mentioned that the ultimate recovery and relative permeabilities of a reservoir are greatly based on the wetting behavior of the reservoir rocks. Adopting the 
wettability of a reservoir affects the production rates, production fluid ratios and the residual saturations. By adjusting the wettability of a system, a higher recovery factor can be achieved.

In 2016, Nwidee et al. [14] performed another study of using nano Zirconium Oxide as an EOR fluid to change the rock wettability. Their study was based on different concentrations ranging from 0 to $0.05 \mathrm{wt} \%$ of nano zirconium-oxide $(\mathrm{ZrO} 2)$. Their results showed that $\mathrm{ZrO} 2$ nanofluid has a great potentials in changing oil-wet limestone towards strongly water-wet condition. The best performance was observed at $0.05 \mathrm{wt} \% \mathrm{ZrO} 2$ nanoparticle concentration which changed an originally strongly oil-wet $\left(152^{\circ}\right)$ calcite substrate towards a strongly water-wet $\left(44^{\circ}\right)$ state. This indicates that $\mathrm{ZrO} 2$ is a good agent for enhanced oil recovery.

\section{Recovery Mechanisms of Nano-EOR}

The use of nanotechnology in EOR started since 2006, which provide several means that would lead to higher hydrocarbon recovery. Nanotechnology can be referred to as the manmade engineering structures whose size ranges from 1 to 100 nanometers. These structures are totally controlled and manipulated at the level of atoms. At this size, the properties of these structures changes significantly from the properties of the bulk particles of the same materials. Most of the changed properties were found to be very beneficial for different engineering and science disciplines. According to Alexandre [15], some of these properties are mechanical properties such as strength and dimensional stability, thermal stability, flame retardancy, chemical resistance and surface appearance.

According to Alexandre [15], Theodore, 2006. [16], and Rezaeyan, 2012 [17] these nanostructures can be classified into four main categories:

1. Nanoparticles: These are nano-granular and nano-crystalline spherical particles.

2. Nanotubes: These could be named nano-fibers or nano-rods such as carbon nanotubes and silica nanotubes.

3. Nano layers: These could be in the form of layered silicates known as anoclays.

4. Nanocomposites: These are made by blending nanoparticles with beneficial characteristics to a resin polymer matrix.

Nowadays, it is extremely noticeable that Nanotechnology has been immerging in most of fields industry. This is why it is given a very high importance through research, experimentation and analysis. Unfortunately, it was not until the last 15 to 20 years, that nanotechnology was introduced to the oil and gas industry and mainly the operations of drilling and production. Nanotechnology introduced special properties of materials for petroleum engineers that guarantees both the strength and the stability of the structures and reduces the amount of devices for engineers to work with.

\section{EXPERIMENTAL WORK}

Brine Preparation: The brine used in this research is a 70,000 ppm brine. $\mathrm{NaCl}$ salt is used in order to prepare this brine. This concentration was chosen as an average value for the Egyptian oil field salinity, in order to be representative to the reservoir formation water since the core samples have been taken from an Egyptian oil field.

Brine and Oil Properties Determination: The brine and oil density were measured in the core lab using pycnometer and the viscosity was measured by Chandler Rolling Ball Viscometer.

Core Properties Identification: The bulk volume, pore volume and porosity were measured using Helium Porosimeter and the Liquid Saturation Method. While the core permeability was measured by using two different methods, the first gas permeameter (using Klinkenberg theory) and liquid permeameter. 
Core Saturation: The core was fully immersed in a beaker containing the prepared brine. The core was then placed in the Vacuum Saturator for a couple of hours so as to make sure the core is fully saturated. This process must be done properly because it could significantly affects the results of the whole experiment.

Nanofluid Preparation: The nanofluids were prepared using the nanoparticles and the prepared brine. Then the nanofluid is placed in a Sonicator (either probe or bath sonicator). The sonication process of the nanofluid takes a couple of hours in order to guarantee full suspension of the nanoparticles in the fluid, as a result from previous work of Adel Salem [18] concerns.

Sonication Process: Sonication is the process through which specific sound waves are forced to pass through a solution in order to agitate the particles inside it. The disruptions caused by these sound waves are used in order to mix solution or speed up the dissolution of solids inside the liquid. Sound wave is made of alternating regions of high pressure and low pressure, so as the sound wave passes through the solution it causes areas of high pressure and areas of low pressure. The frequency of the sound waves is a measure of how often the particles of the substance vibrate. The frequency of the sound waves used in the sonication of nanoparticles is always above $20 \mathrm{kHz}$ and these waves are considered ultrasonic waves. Increasing the frequency leads to better agitation and suspension of the nanoparticles inside the solution (Diagenode, 2009 [19]). In this experiment, a probe sonicator is used in order to do the sonication process. The sonicator is of a frequency of $50 \mathrm{kHz}$, and can work with an amplitude ranging from $30 \%$ to $90 \%$.

Flooding Operation: The core is placed in the core flooding device (Figure 2). A large amount of oil is injected into the core under a relatively high pressure difference. This allows the oil to replace the brine existing in the core and pushed it outside the core. This process stops when there is no brine produced from the core at all, i.e. the water cut in the production face is zero. In this case, the core becomes representative to an oil reservoir and the remaining amount of brine existing inside the core is considered to be the connate water. The volume of brine produced is calculated through the graded tubes and it is considered to be the volume of oil in place. On the other hand the amount of pore volume remaining is calculated and it is considered to be the volume of the interstitial water. Through these data the $S_{w c}$ and $S_{o}$ can be calculated.

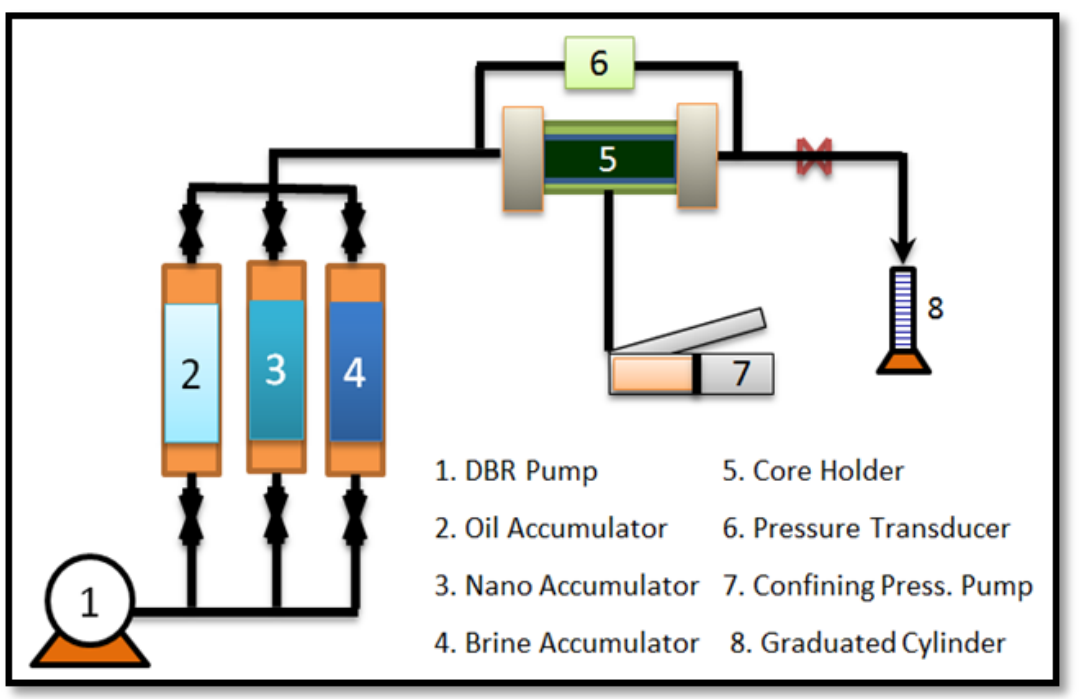

Fig. 2: Schematic diagram of the flooding apparatus 


\section{Alumina Nanoparticles $\left(\mathrm{Al}_{2} \mathrm{O}_{3}\right)$ Identification}

Type and size of the Alumina nanoparticles: The nano Alumina particles have been prepared in Egyptian Petroleum Research Institute (EPRI). The prepared Alumina is a nano size highly crystalline alpha type alumina powder. It has been synthesized by the microwave combustion approach at $900 \mathrm{w}$ for $5 \mathrm{~min}$ with metal/fuel molar ratio as 1:3. The size of the alumina nanoparticles can be identified through applying the High Resolution Transmission Electron Microscopy (HRTEM) Test. The following images of the transmission electron microscopy (TEM) shows very fine particles in the range of $1.5-5 \mathrm{~nm}$ with a spherical shape. Figure 3, and Figure 4 give an indication about the size of the alumina nanoparticles through an HRTEM photo.

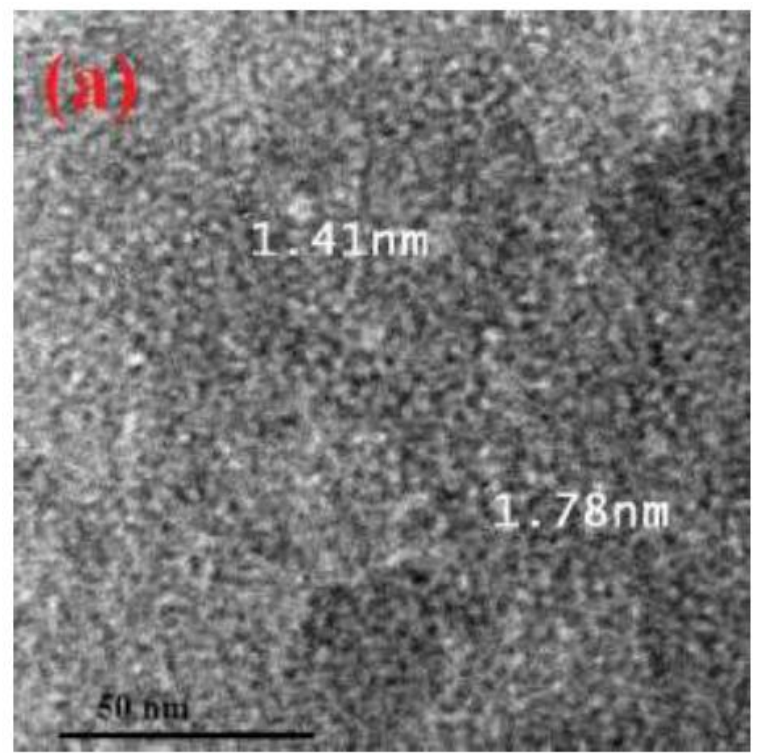

Fig. 3. HRTEM of Alumina Nanoparticles $50 \mathrm{~nm}$

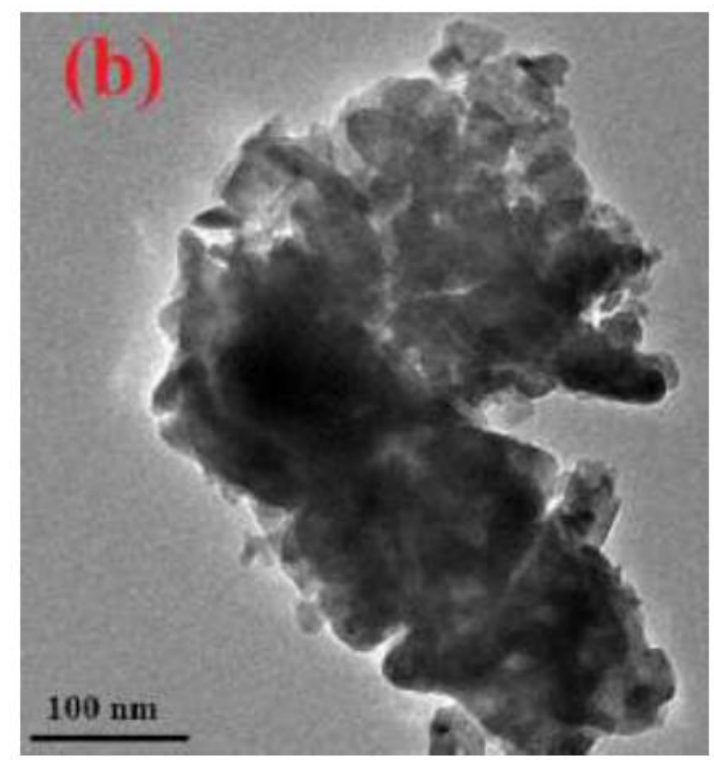

Fig. 4. HRTEM of Alumina Nanoparticles $100 \mathrm{~nm}$

Structural Analysis of Alumina nanoparticles: In order to investigate the structural analysis of the alumina nanoparticles, an X-ray diffraction test was performed. As shown in Figure 5, the presence of a highly crystalline complete single phase $\alpha-\mathrm{Al}_{2} \mathrm{O}_{3}$ can be confirmed. The XRD pattern shows a match to the JCPDS 10-0173. Figure 5 shows the data resulted from the $\mathrm{X}$-ray diffraction test performed at EPRI:

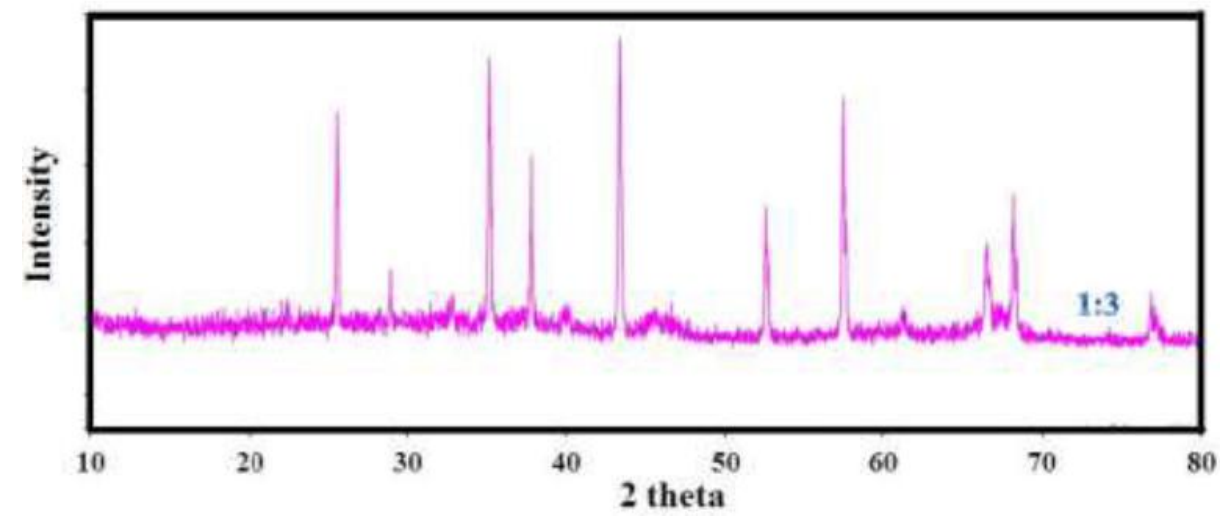

Fig. 5. X-Ray Diffraction of Alumina Nanoparticles

Water Flooding: The brine is injected into the core, placed in the core flooding device, under a relatively high pressure difference. The pumping rate used through this work is very small in order to obey Darcy Law. The volumes of oil and brine produced are measured and then their flow rate are calculated. The pressure difference and the time for the process are also monitored at each step. By using all of these calculated parameter, the recovery factor, 
and relative permeability curves were calculated and plotted as will be seen in the next section.

Injection of Nanofluid: nanofluids have been prepared with different concentrations and used to enhance the oil recovery along with investigating the main recovery mechanisms. The nano particles used is formulated as mentioned before from Aluminum Oxide (Alumina $\left.\mathrm{Al}_{2} \mathrm{O}_{3}\right)$.

The injection of $\mathrm{Al}_{2} \mathrm{O}_{3}$ nanofluid inside an oil reservoir would lead to a significant decrease in the residual oil saturation, an increase in the amount of oil produced and so an increase in the field overall ultimate recovery. Injection of $\mathrm{Al}_{2} \mathrm{O}_{3}$ nanofluids always occurs in the tertiary recovery phase (after the water flooding) due to their high cost and low availability. In this experiment, the nanofluids are prepared in a brine solution of $70000 \mathrm{ppm}$ salt concentration. This is in order keep up with the formation water existing inside the reservoir.

The pre-prepared nano fluid is injected in the core plug with different concentrations. The concentrations used were $3 \mathrm{~g} / \mathrm{L}, 5, \mathrm{~g} / \mathrm{L}, 7 \mathrm{~g} / \mathrm{L}$, and $10 \mathrm{~g} / \mathrm{L}$. These concentrations were used to investigate the effect of nano fluid on the recovery factor, wettability alteration, and the relative permeability curves. The detailed results of all of these parameters will be explained in the next sections.

Core Cleaning: The core sample was removed from the core flooding device and placed inside a Soxhlet or Dean-Stark apparatus. The core must be fully immersed inside the solvent in order to guarantee a maximum cleaning. The core sample must be left in the apparatus overnight for proper cleaning. The core is then placed inside an oven in order to evaporate all the fluids existing inside it. At this point, the core becomes ready for being used in another experiment.

The experimental procedure was performed as follow:

1. The saturated core plug was placed inside the cell of the core flooding device.

2. A confining pressure was made on the core in order to make sure that all the fluid injected will pass through the core and there are no leaks inside the cell. The confining pressure was made by a hydraulic pump and is fixed at $500 \mathrm{psi}$

3. A large amount of oil was placed inside a vessel in the core flooding device where a pressure is applied upon it, and the oil then gets injected with a relatively high pressure inside the rock sample.

4. The brine solution is allowed to be removed from the core sample towards a graduated tube.

5. The volume of the brine solution was calculated using the graduated tube and it is considered as a representative of the amount of oil in place.

6. The connate water saturation was then calculated

7. This experiment may take a couple of hours in order to make sure that no more brine solution can be removed from the rock core sample.

\section{RESULTS AND DISCUSSIONS}

Table 1 lists the results that were determined after the initiation process. It indicates that the amount of oil in place is $10.6 \mathrm{cc}$ and the connate water saturation is $32.33 \%$.

Table 1. Initial state of the core plug

\begin{tabular}{l|c}
\hline Parameter, & Amount \\
\hline Pore volume, cc & 15.664 \\
\hline Volume of oil in place, cc & 10.6 \\
\hline Oil saturation, \% & 67.67 \\
\hline Connate water saturation, \% & 32.33 \\
\hline
\end{tabular}




\section{Case \#1: Water Flooding (Base Run)}

In this scenario, the pre-prepared core sample was flooded by water as a secondary recovery. Starting by injecting 0.2 pore volume $(0.2 \mathrm{PV})$ and check the recovery we get from the flooding operation and so on. With an increasing these injected water, the experimental work stopped when we get the maximum recovery factor. Therefore, several parameters were calculated and presented. All the results are then collected in a sheet for calculating the water cut, the amount of residual oil and the oil recovery factor.

Figure 6 depicts the relationship between the calculated recovery factor and the pore volume injected for the base run. It shows an increase in the oil recovery factor as the injected pore volume increased. The water injection continues till no more oil produced and all output fluid is water or up to the economic limit. The recovery factor was determined to be $60.38 \%$ of the OOIP.

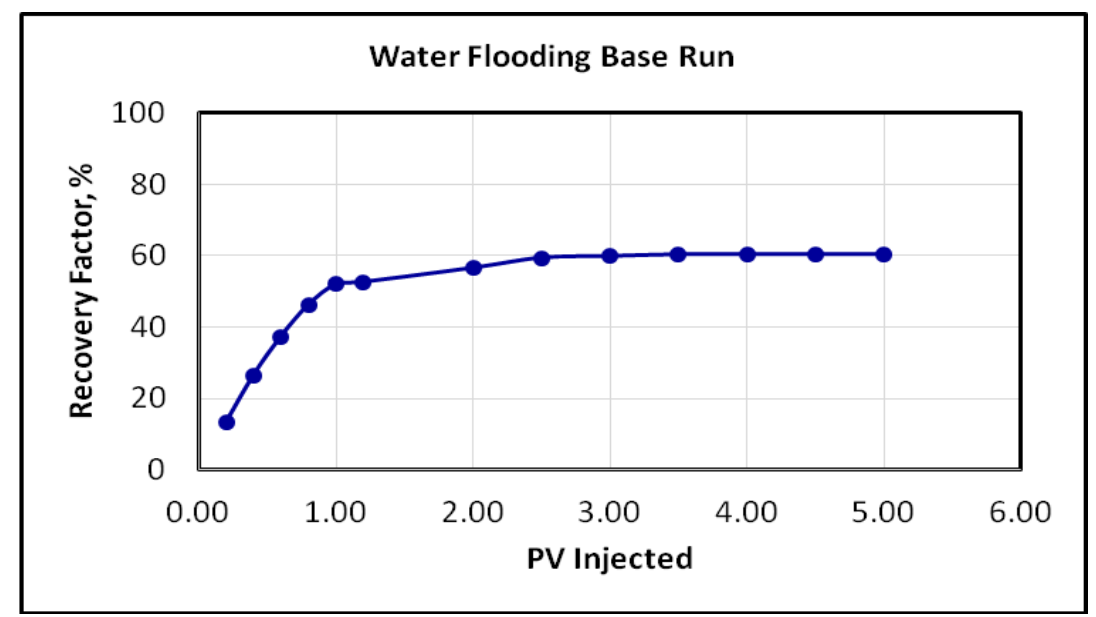

Fig. 6. Recovery factor vs. pore volume injected for water flooding base run.

The original relative permeability curve for this run is presented in Figure 7. It is noticed that the intersection point lies after $50 \%$ water saturation. This indicates that the wettability of sample is water wet. The intersection point is achieved at about $67.5 \%$ water saturation. The distance between the intersection point at the $50 \%$ water saturation gives an indication about the degree of rock wettability. This fact will be discussed later on (after injecting the nanofluid) to investigate any kind of wettability change as a result of nanofluids injection.

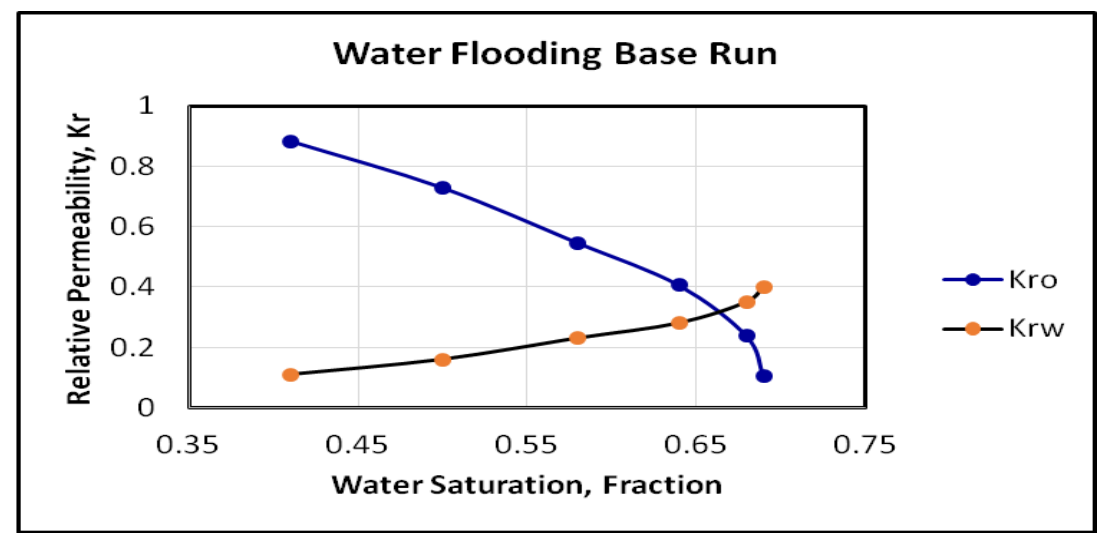

Fig. 7. Relative Permeability Curve for water flooding base run.

Case \#2: Nano Alumina Flooding ( 3 g/L)

In this experiment, the concentration of the $\mathrm{Al}_{2} \mathrm{O}_{3}$ nanofluid is 3 grams per liter of brine solution. This represents about $3000 \mathrm{ppm}$ which means $0.3 \%$ wt. This concentration is considered as one of the most commonly used concentration in the field of research of nanoparticles. 


\section{Preparation of the Alumina Nanofluid}

a) Using a very sensitive balance, weigh $0.15 \mathrm{~g}$ of Alumina Nanoparticles

b) Using a graduated beaker, bring a $50 \mathrm{ml}$ brine solution

c) Place the tip of the sonicator inside beaker where the alumina nanoparticles are added to the brine solution

d) The Sonicator is adjusted to an amplitude of 50\% with 1 pulse on and 1 pulse off.

e) The sonication process takes 1-3 hours until it is observed that there are no nanoparticles precipitated at the bottom of the beaker.

\section{Injection of the Alumina Nanofluid}

a) The nanofluids is placed inside the vessel while the vessel is placed on a magnetic stirrer and a magnet is placed inside the vessel.

b) The vessel is then closed properly in order to make sure that all the pressure is used to push the fluid inside the rock core sample.

c) A volume of 0.2 pore volume is placed inside the vessel and a constant pressure is applied in order to inject the alumina nanofluid inside the rock sample.

d) The amount of water produced, oil produced, time of production, and the pressure difference are determined from the device and recorded for further calculations.

e) Steps (c) and (d) are repeated with different volumes of 0.4 pore volume, 0.6 pore volume, 0.8 pore volume and 1.0 pore volume.

f) All the results are then collected in a sheet for calculating the water cut, the amount of residual oil, the incremental oil recovery and the ultimate oil recovery. The experimental procedure will be the same for all experiments.

Figure 8 represents the oil recovery factor resulting from the injection of the first concentration of the alumina nanofluid $(3 \mathrm{~g} / \mathrm{L})$ in terms of the pore volumes injected. The maximum recovery factor achieved by this concentration is $74.38 \%$. This means the recovery factor is increased by about $14 \%$ over that of water flooding base run (case \#1).

After performing this scenario, the relative permeability was measured and presented on Figure 9. This relative permeability curve indicates that there has been a favorable change in the wettability of the rock. According to Figure 9 the new point of intersection being shifted towards the right hand side indicates that the wettability of the rock sample increased towards the water wet. This in turns leads to better mobility ratio and then a significant increase in the ultimate oil recovery as it was proven in Figure 8. The point of intersection here lies at a value of $72.5 \%$ water saturation. This is means that the intersection point has been shifted by $5 \%$ $(72.5 \%-67.5 \%)$ to the right hand side.

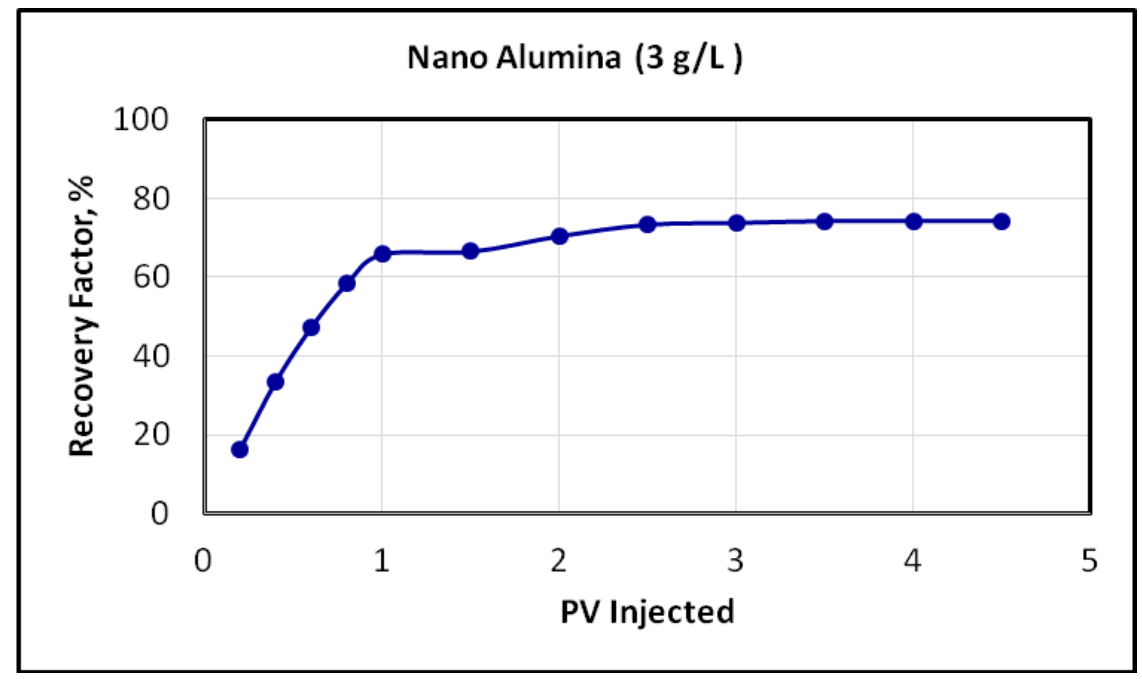

Fig. 8. Recovery factor vs. pore volume injected for Nano Alumina (3 gram/L). 


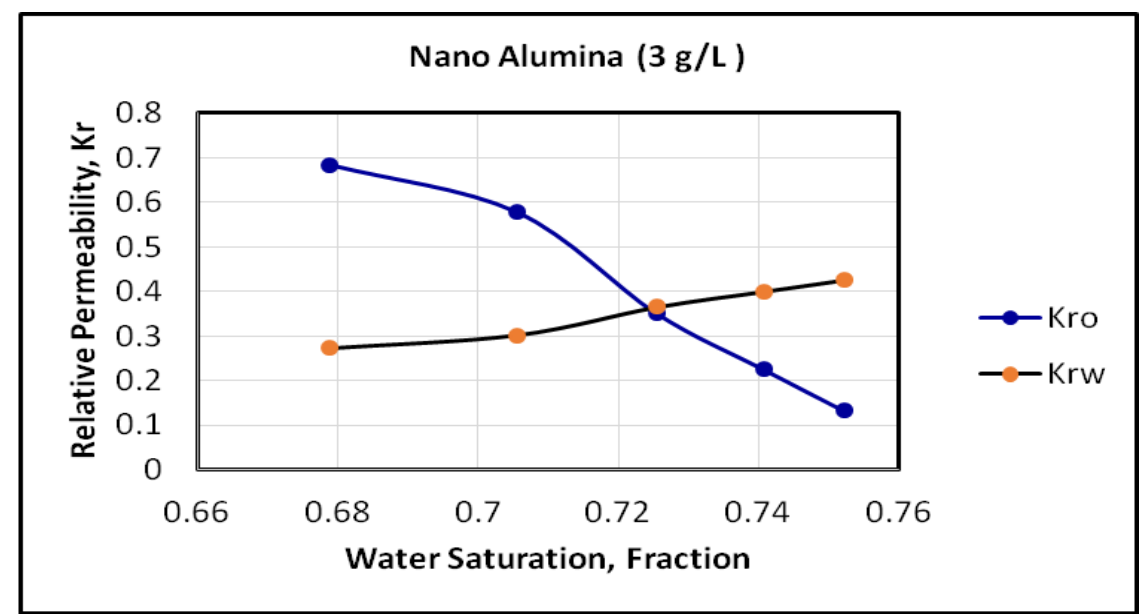

Fig. 9. Relative permeability curve for Nano Alumina 3 gram /L run.

\section{Case \#3: Nano-Alumina Flooding ( $5 \mathrm{~g} / \mathrm{L})$}

In this experiment, the concentration of the $\mathrm{Al}_{2} \mathrm{O}_{3}$ nanofluid is 5 grams per liter of brine solution $(0.25 \mathrm{~g}$ in $50 \mathrm{~mL})$ and the sonication process takes from 2-4 hours.

Figure 10 represents the oil recovery factor resulting from injecting the second concentration of the alumina nanofluid $(5 \mathrm{~g} / \mathrm{L})$ in terms of the pore volumes injected. The recovery factor increased as the injected pore volume increased. The run ceased when the recovery factor becomes constant, so this run stopped at $5 \mathrm{PV}$ injected. This concentration increased the recovery factor by $0.71 \%(75.09 \%-74.38 \%)$ over the previous Alumina concentration $(3 \mathrm{~g} / \mathrm{L})$ and increased by about $14.71 \%$ (75.09\%-60.38\%) over the water flooding base run.

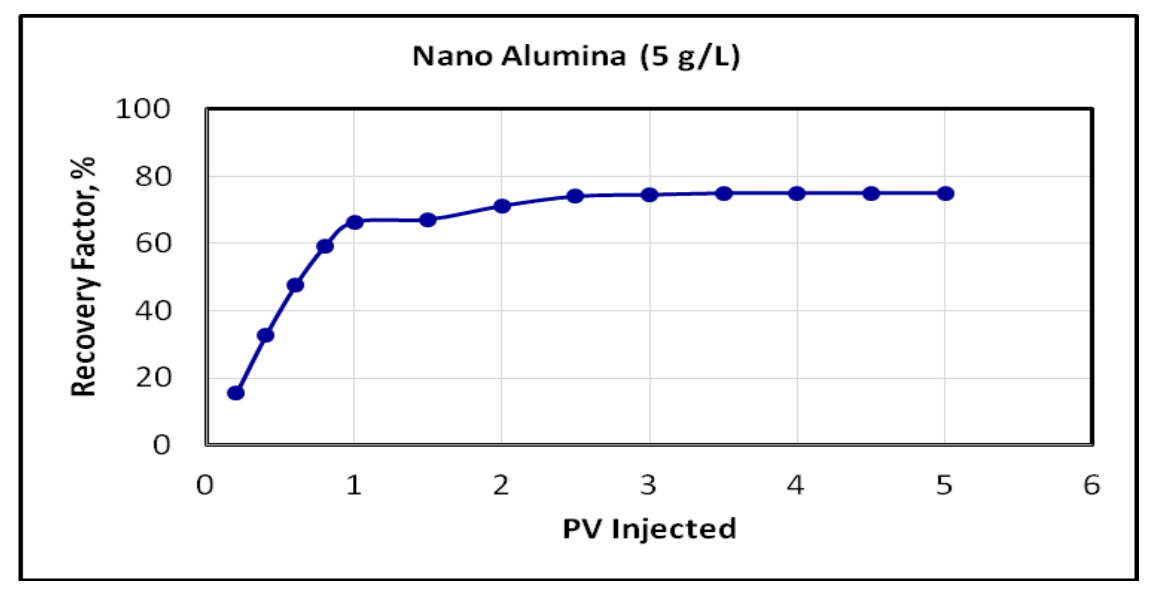

Fig. 10. Recovery factor vs. pore volume injected for nano Alumina 5 gram /L run.

After performing this run, the relative permeability was measured and presented on Figure 11. It is noticed that the intersection point moved to about $73.5 \%$ water saturation. This is means that it moved about $1 \%(73.5 \%-72.5 \%)$ water saturation to the right hand side, which means the core became more water wet than the previous case. The intersection point is moved about $6 \%(73.5 \%-67.5 \%)$ water saturation over the intersection point of water flooding base run. All of these results indicate that the core sample became more water wet than before. This relative permeability curve indicates that there has been a favorable change in the wettability of the rock. This in turns leads to a better mobility ratio and then a significant increase in the ultimate oil recovery. 


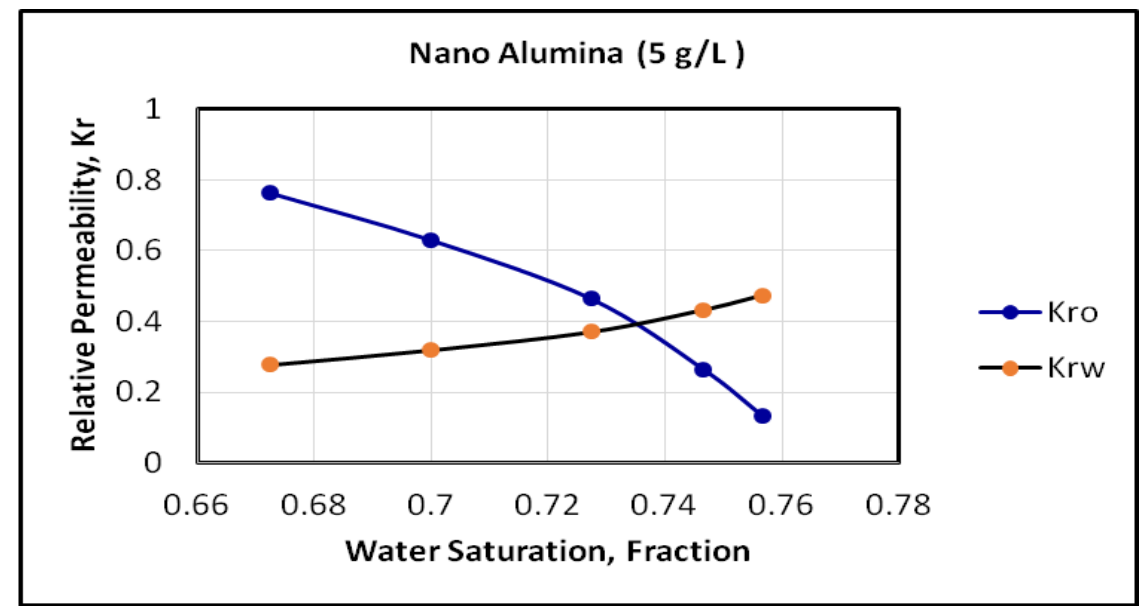

Fig.11. Relative Permeability Curve for Alumina 5 gram/L run

Case \#4: Nano Alumina Flooding ( $7 \mathrm{~g} / \mathrm{L})$

In this experiment, the concentration of the $\mathrm{Al}_{2} \mathrm{O}_{3}$ nanofluid is 7 grams per liter of brine solution $(0.35 \mathrm{~g}$ in $50 \mathrm{ml})$. The sonicator was set at an amplitude of $60 \%$ and the sonication process lasted from 2.5-4 hours.

Figure 12 represents the oil recovery factor resulting from the injection of the third concentration of the alumina nanofluid $(7 \mathrm{~g} / \mathrm{L})$ in terms of the pore volumes injected. In this case we stopped injection at about $5 \mathrm{PV}$. The maximum recovery achieved is about $76.13 \%$ with about $1.04 \%$ incremental recovery than the previous case $(5 \mathrm{~g} / \mathrm{L}$ run $)$, and about $15.75 \%$ than water flooding base run.

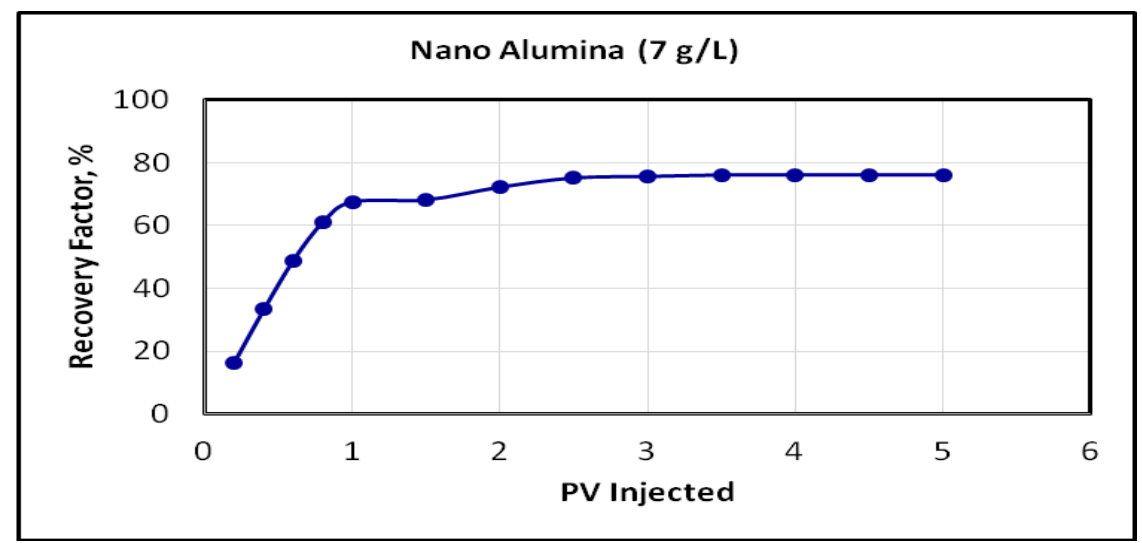

Fig. 12. Recovery factor vs. pore volume injected for nano Alumina 7 gram /L run.

To explain such increase in the recovery factor than the previous nanofluids injection and water flooding, the relative permeability was measured and plotted on Figure 13. This relative permeability curve indicates that there has been a more and more favorable change in the wettability of the rock sample. According to Figure 13 The new point of intersection being shifted more and more towards the right hand side indicates that the wettability of the rock sample has increased more and more towards the water wet region. This in turns leads to a better mobility ratio and then a significant increase in the ultimate oil recovery. The point of intersection here lies at a value of $75.5 \%$ water saturation. Consequently, a clear observation could be taken here that the values of $S_{w}$ are shifting towards having more water wet rock surface and this is so effective in increasing the amount of oil produced. 


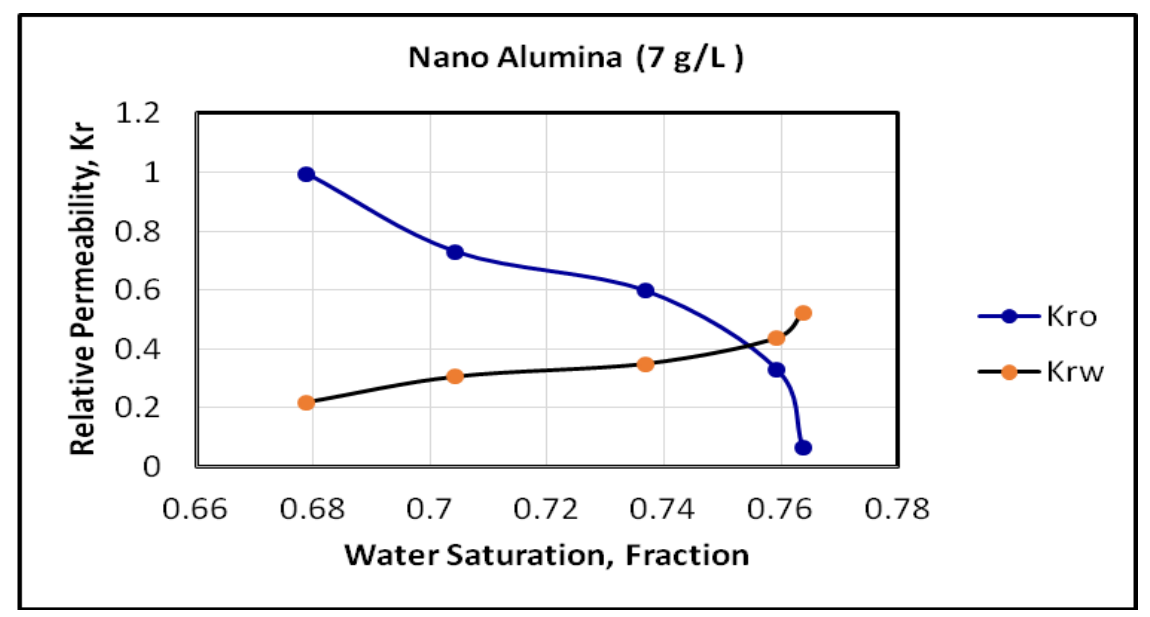

Fig. 13. Relative Permeability Curve for Alumina $7 \mathrm{gram} / \mathrm{L}$ run.

\section{Case \#5: Nano Alumina Flooding (10 g/L)}

In this case, the concentration of the $\mathrm{Al}_{2} \mathrm{O}_{3}$ nanofluid injected is 10 grams per liter of brine solution $(0.50 \mathrm{~g}$ in $50 \mathrm{ml})$. The sonicator was set at an amplitude of $60 \%$ and the sonication process lasted from 2.5-4 hours.

The results of this case are depicted on Figure 14. The recovery factor (RF) increased as the injected PV increased. The maximum RF is $81.13 \%$. with about 5\% (81.13\% - 76.13) incremental recovery than the previous case and about $20.75 \%(81.13 \%-60.38 \%)$ than water flooding base run. This incremental recovery is attributed to many suspected parameters, from these the relative permeability and rock wettability of the core. Therefore, after performing this flooding, the relative permeability was measured and plotted on Figure 15.

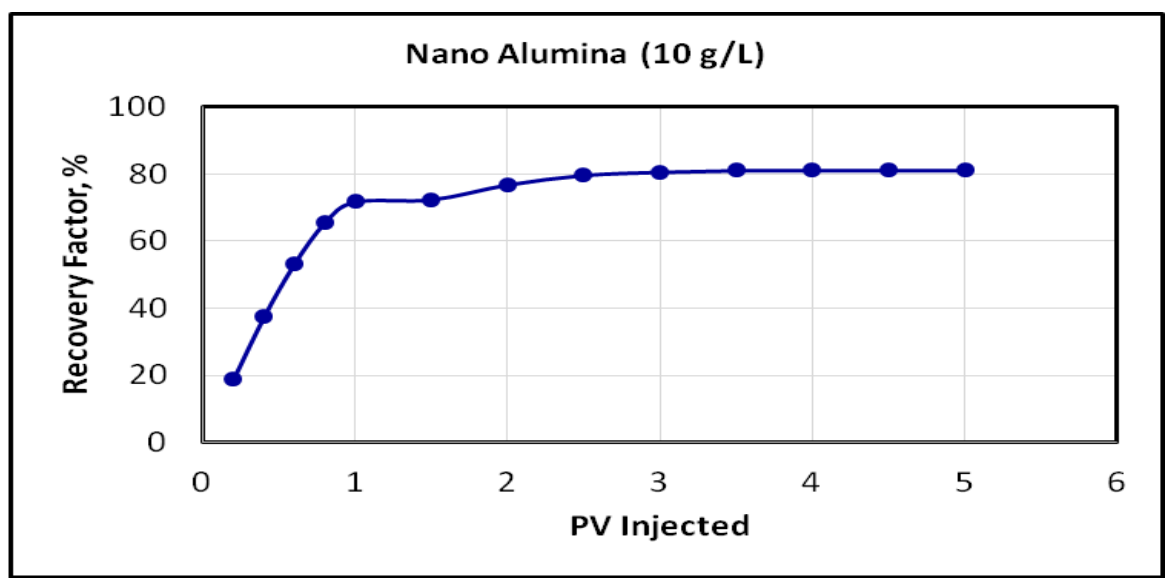

Fig. 14. Recovery factor vs. pore volume injected for Nano Alumina 10 gram/L run.

This relative permeability curve indicates that there has been a more and more favorable change in the wettability of the sandstone rock sample. According to Figure 15, the new point of intersection being shifted more and more towards the right hand side indicates that the wettability of the rock sample increased more and more towards the water wet region. This in turns leads to a better mobility ratio and then a significant increase in the ultimate oil recovery. The point of intersection here lies at a value of $79 \%$ water saturation which is a way better if compared to the initial value which was only $67.5 \%$ water saturation of water flooding base run. This indicates the significant change of rock wettability as a result of alumina nanoparticles injection. This favorable change led to a great increase in the ultimate oil recovery. 


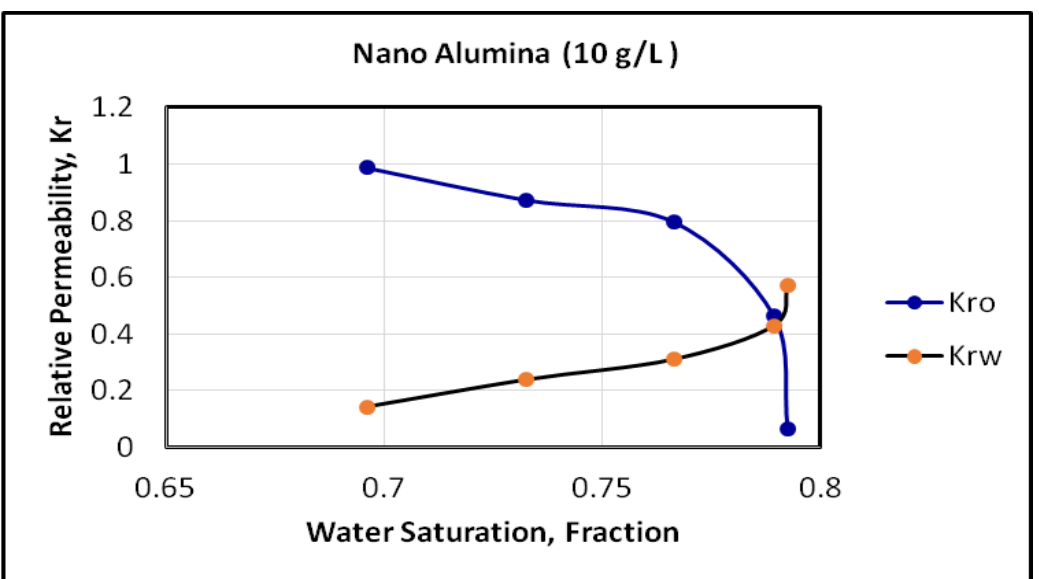

Fig. 15. Relative Permeability Curve for Alumina 10 gram/L run.

\section{Case \#6: Nano Alumina Flooding (15 g/L)}

In this scenario, the concentration of the $\mathrm{Al}_{2} \mathrm{O}_{3}$ nanofluid is 15 grams per liter $(0.75 \mathrm{~g}$ in 50 $\mathrm{mL}$ ) and the sonication process lasted from 3-4 hours.

Figure 16 shows that it is useless to use this high concentration of $15 \mathrm{~g} / \mathrm{L}$ nano alumina. The excessive precipitation of the alumina nanoparticles at surface of the grains located at the pore spaces lead to plugging those pores. Thus is what we found after getting this lowest RF.

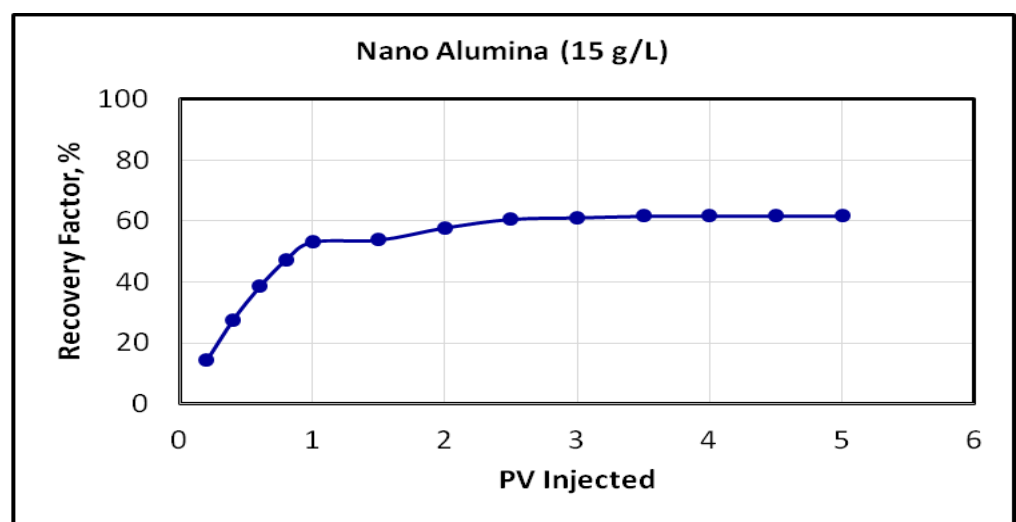

Fig. 16. Recovery factor vs. pore volume injected for Nano Alumina 15 gram / L run.

By the same manner, relative permeability was measured and presented on Figure 17. As depicted from the figure, the intersection point of the relative permeability curve is lowered relative to that of the previous run. It decreased to about $66.64 \%$ water saturation. This intersection point even less than what we get from water flowing base run. This was attributed to that the higher concentration of nanoparticle plugs the pores of the rock sample.

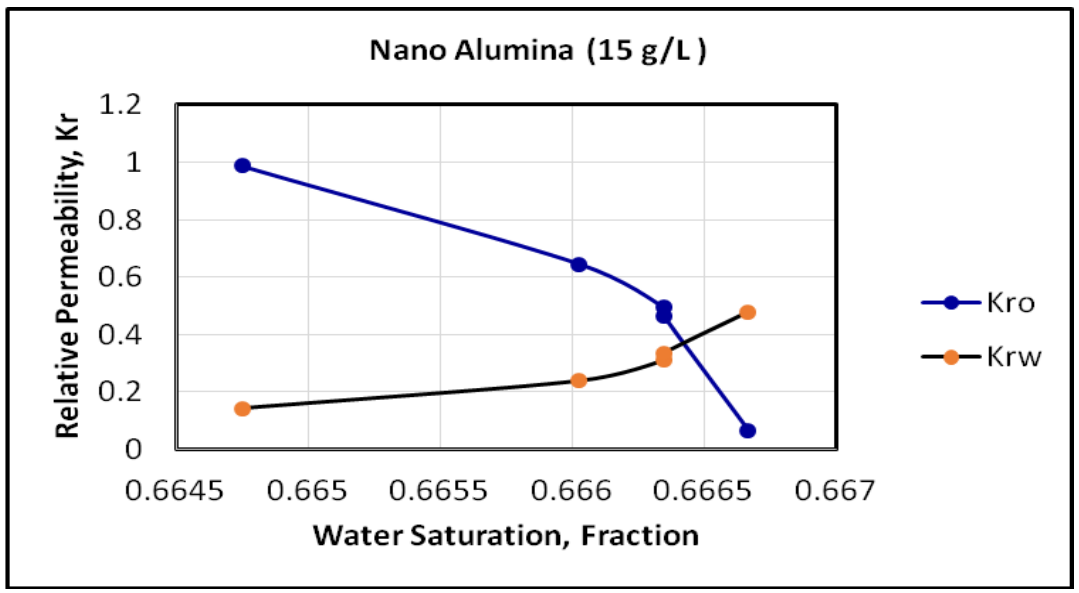

Fig. 17. Relative permeability curve for Nano Alumina 15 gram/L run. 


\section{COMPARISON BETWEEN THE ALUMINA NANOFLUIDS}

The injection of alumina nanofluids has proved its significant success in increasing the amount of oil recovered and reaching a higher ultimate oil recovery. Although different concentrations of the alumina nanoparticles have been used through the experimental work, they all have shown an increase in the recovery of oil except the last one (15 g/L run). It can be observed that by increasing the concentration of the nanoparticles in the displacing brine, an increase in the amount of oil recovery was obtained. However, in the last experiment, when adding a nanofluid with concentration of 15 grams per liter, there has been a clear decrease in the amount of the oil produced. This incidence occurred because at high concentrations of nanoparticles, the nanofluid may cause blockage of the pores (either due to precipitation or hanging) in the core sample throats. The quick adsorption of the nanoparticles on the surface of the grains at the pores causes its blockage. These blocked pores, causes a significant increase in the differential pressure and a sharp decrease in the amounts of oil produced. They do not allow the nanofluid located inside the vessel to be pressured through the core sample. Consequently the values of these concentrations should be taken into consideration when working on a reservoir scale in order to not to cause sharp reductions in reservoir the permeability. Figure 18 is a comparison between the recovery factors obtained by using different concentrations of alumina nanofluids. It can be observed that the optimum concentration of alumina nanoparticles is $0.01 \%$ (10 grams per 1 liter). According to this figure, the incremental oil recovery at that concentration reached up to $20.75 \%$ higher than that by conventional water flooding. This significant increase shows how much the use of nanoparticles could enhance the ultimate oil recovery.

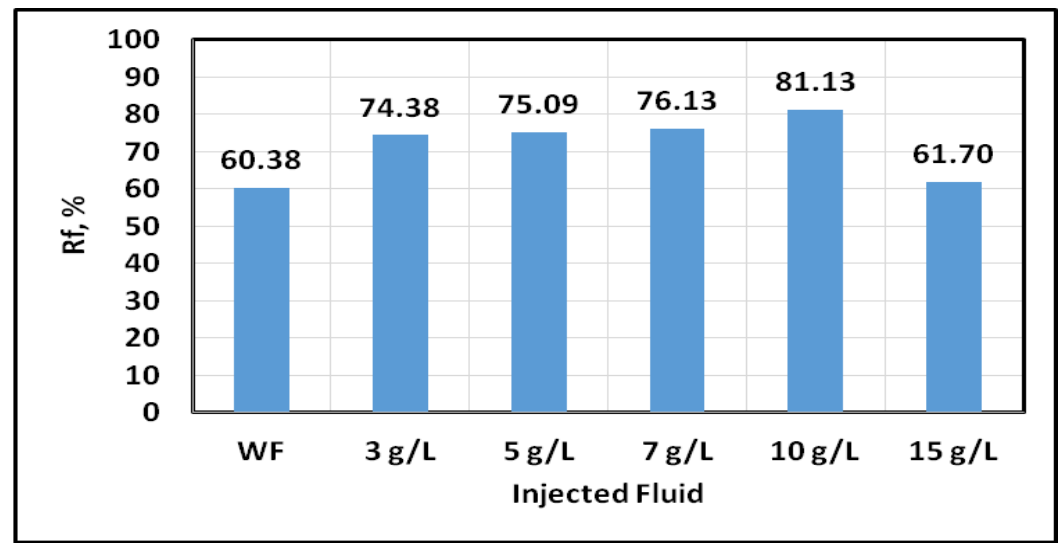

Fig. 18. Comparison between recovery factors by different nano Alumina concentrations and water flooding

Figure 19 shows the same results represented in Figure 17 but in different manner.

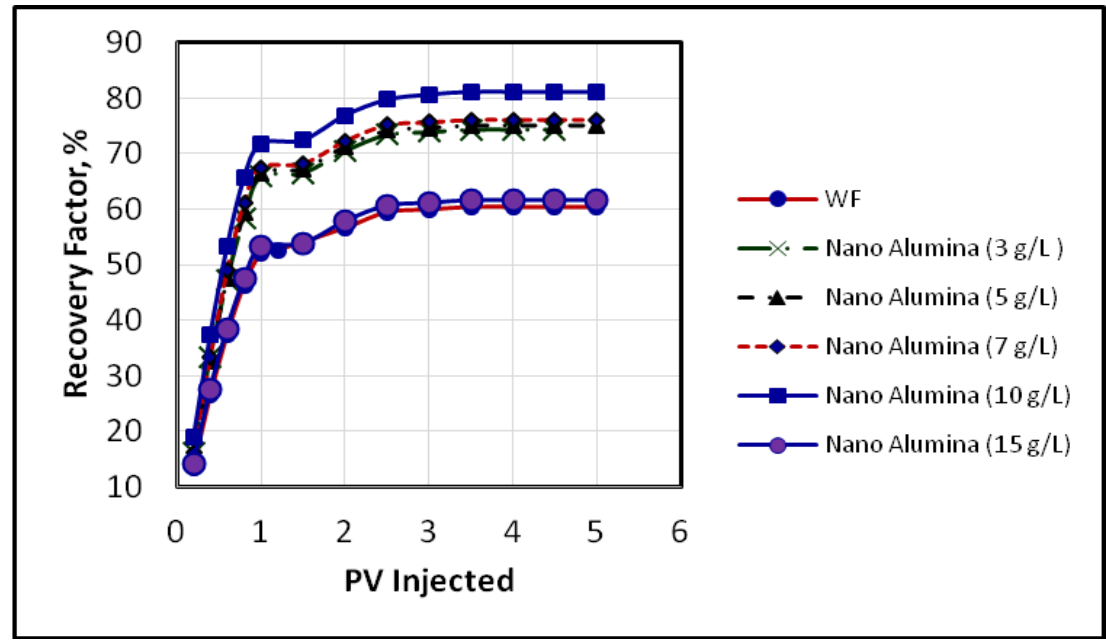

Fig. 19. Effect of Alumina nanofluid concentration on the oil recovery factor 


\section{Wettability Alteration by Nano Alumina}

To investigate the effect of nano fluid on the rock wettability, a set of experiments has been performed with different nano alumina concentrations (from $0 \mathrm{~g} / \mathrm{l}$ to $10 \mathrm{~g} / \mathrm{l}$ ). Then the contact angle was measured in each case using a high resolution camera. The results of these runs are shown on Figure 20, while Table 2 lists the values of the measured contact angles. These results illustrate that as the concentration increases the contact angel increases, which indicates a wettability alteration toward water wet. The results confirm the previous findings from the relative permeability curves and the intersection points. This result is very important and crucial to explain the incremental recovery factor by nano alumina over the conventional water flooding.

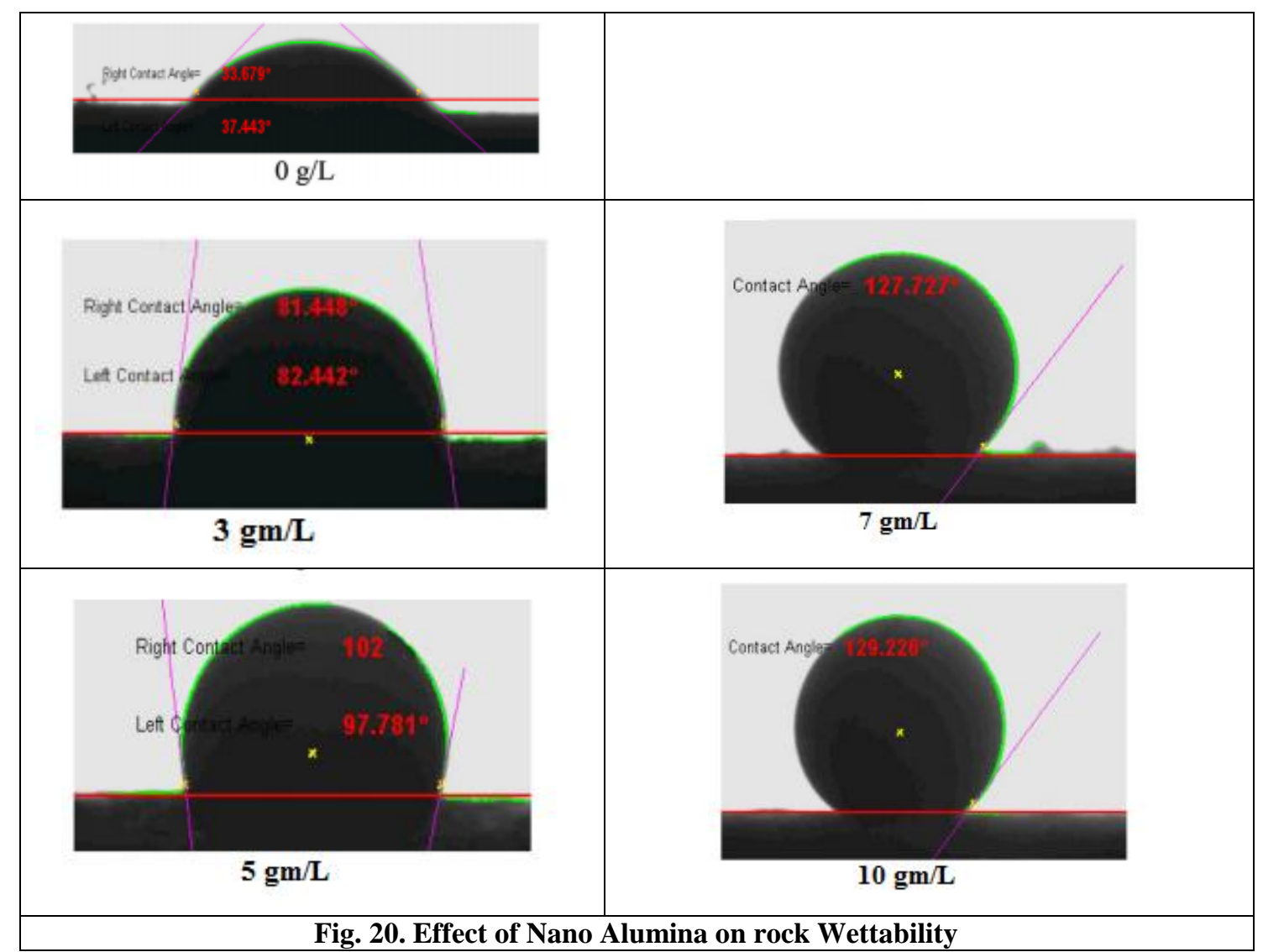

Table 2: Contact angle for different nano alumina concentration

\begin{tabular}{c|c}
\hline $\begin{array}{c}\text { NANO ALUMINA } \\
\text { CONCENTRATION, G/L }\end{array}$ & CONTACT ANGLE, $^{\mathbf{}}$ \\
\hline $\mathbf{0}$ & 37.443 \\
$\mathbf{3}$ & 82.442 \\
$\mathbf{5}$ & 97.781 \\
$\mathbf{7}$ & 127.727 \\
$\mathbf{1 0}$ & 129.226 \\
\hline
\end{tabular}

Normally the intersection point on the relative permeability curve indicates the degree of the rock wettability at least qualitatively. As it is known, as the intersection point corresponds to a water saturation higher than $50 \%$, this indicates a water wet rock, but if the intersection point corresponds to a water saturation lower than $50 \%$, it means the rock is oil wet. Based on this rule, as the intersection point is far away from the $50 \%$ water saturation, it means the rock is 
strongly wet. In other words, if it is close to $90 \%$ water saturation that means a strongly water wet rock meanwhile if it is in the opposite direction, it means it is strongly oil wet.

The results of the present research indicate that as the nano alumina concentration increases, the intersection point moves to the right hand side, which means that the rock becomes more water wet, as shown on Figure 21. The figure indicates also that for $15 \mathrm{gram} / \mathrm{L}$ concentration the intersection point moved back to a less water saturation, which means the degree of water wettability becomes less than the previous nano Alumina concentration $(10 \mathrm{~g} / \mathrm{L})$. All of these results explain why all nano alumina concentrations resulted higher recovery factor (than conventional water flooding) except for the $(15 \mathrm{~g} / \mathrm{L})$ concentration.

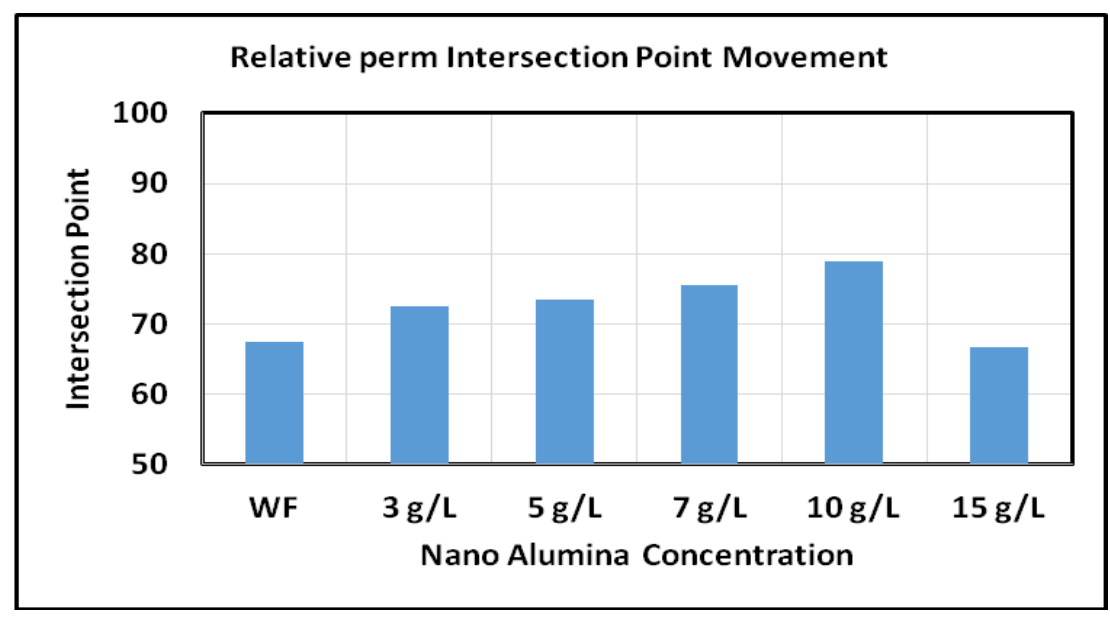

Fig. 21. Intersection point of relative perm movement

\section{CONCLUSIONS}

Based on the experimental work conducted in the present research, the following conclusions can be drawn:

1. The potential of nanotechnology to improve the design and execution of chemical EOR has been addressed. This study provides a valuable research work about Alumina nanoparticles applications for enhanced oil recovery.

2. As the Nano Alumina concentration increased as the recovery factor increased for 3 $\mathrm{g} / \mathrm{L}$ to $10 \mathrm{~g} / \mathrm{L}$ concentrations.

3. The effect of different concentrations of Alumina nanoparticles on oil recovery has examined, the ultimate recovery factor of $81.13 \%$ is achieved at $10 \mathrm{~g} / \mathrm{L}$. while $15 \mathrm{~g} / \mathrm{L}$ Nano Alumina concentration has resulted in the lowest recovery factor.

4. $\mathrm{Al}_{2} \mathrm{O}_{3}$ has proved a great success in their ability to a slightly alter or change the wettability of the sandstone rock to be more water wet.

5. After nanofluids injection, the intersection point on the relative permeability curves indicate that the core sample wettability has changed to be more water wet. The biggest difference in the intersection point (11.5\%) was achieved with $10 \mathrm{~g} / \mathrm{L}$ concentration.

6. The contact angles, as a means of rock wettability were measured and confirmed the recovery factor achieved for all Nanofluid used.

\section{Acknowledgments}

The authors are highly appreciate British University in Egypt (BUE), Future University in Egypt (FUE) and Egyptian Petroleum Research Institute (EPRI) for using some of their research equipment and core plugs to conduct the experimental part of this work. 


\section{REFERENCES}

1. Das, S. K., Choi, S. U. S., Yu, W., and Pradeep, T.: "Nanofluids Science and Technology" John Wiley \& Sons, Inc Publishing, Hoboken, NJ, ISBN: 0470074736, 2008.

2. Ragab, Adel M. Salem.: "Mitigation of Formation Damage by Designing a Novel Nanoparticles Mud", Oil Gas European Magazine, page 104 - 109, Volume 40 (2), 2014.

3. Ragab, Adel M. Salem, and El-Diasty, Abdelrahman, I.: “Applications of Nanotechnology in the Oil and Gas Industry: Latest trends Worldwide and Future Challenges in Egypt", SPE paper 164716, presented at the North Africa Technical Conference and Exhibition (NATC 2013) held in Cairo, Egypt, April 15-17, 2013

4. Ogolo, N. A., Olafuyi, O.A., and Onyekonwu, M.O.: "Enhanced Oil Recovery Using Nanoparticles, SPE 160847, presented at the SPE Saudi Arabia Section Technical Symposium and Exhibition held in Al-Khobar, Saudi Arabia, April 8-11, 2012.

5. Alomair, O. A., Matar, K. M., \& Alsaeed, Y. H. : "Nanofluids Application for Heavy Oil Recovery" Society of Petroleum Engineers. Oct. 14, 2014.

6. Ragab, Adel. M. Salem, and Hannora, A. E.: "A Comparative Investigation of Nano Particle Effects for Improved Oil Recovery - Experimental Work" Society of Petroleum Engineers, Oct.11, 2015.

7. Salem, Adel and Hannora, A. E.: "An Experimental Investigation of Silica Nano Particles for Enhanced Oil Recovery Applications" Society of Petroleum Engineers, Sept. 14, 2015.

8. Bradford, S. A., Simunek, J., Bettahar, M., van Genuchten, M. T., \& Yates, S. R.:“ Modeling Colloid Attachment, Straining, and Exclusion in Saturated Porous Media" Environmental Science \& Technology, 37(10), 2242-2250., 2003

9. Rodriguez Pin, E., Roberts, M., Yu, H., Huh, C., \& Bryant, S. L.: "Enhanced Migration of Surface-Treated Nanoparticles in Sedimentary Rocks" Society of Petroleum Engineers, Jan. 1, 2009.

10. Caldelas, F. M., Murphy, M., Huh, C., \& Bryant, S. L.: "Factors Governing Distance of Nanoparticle Propagation in Porous Media". Society of Petroleum Engineers, Jan. $1,2011$.

11. Torsater, O., Li, S., \& Hendraningrat, L.: "A Coreflood Investigation of Nanofluid Enhanced Oil Recovery in Low-Medium Permeability Berea Sandstone" Society of Petroleum Engineers, April 8, 2013.

12. Li, S., Genys, M., Wang, K., \& Torsæter, O.: "Experimental Study of Wettability Alteration during Nanofluid Enhanced Oil Recovery Process and Its Effect on Oil Recovery" Society of Petroleum Engineers, Sept. 14, 2015.

13. Sheshdeh, M. J. : "A Review Study of Wettability Alteration Methods with Regard to Nano-Materials Application" Society of Petroleum Engineers, April 22, 2015.

14. Nwidee, L. N., Al-Anssari, S., Barifcani, A., Sarmadivaleh, M., \& Iglauer, S.: "Nanofluids for Enhanced Oil Recovery Processes: Wettability Alteration Using Zirconium Oxide" Offshore Technology Conference, March 22, 2016.

15. Alexandre, M. : "Polymer Layered Silicate Nanocomposites" Material Science and Engineering, 1-63., 2000.

16. Theodore, L.: "Nanotechnology: Basic Calculations for Engineers and Scientists", New Jersey: John Wiley and Sons Inc. 2006.

17. Rezaeyan, A.: "A Novel Movement in Oil and Gas Exploration and Production Associated with Nanotechnology", Research Gate, 2012.

18. Ragab, Adel M. Salem: "Unlocking Reservoir Potential using Robust Hybrid Nanoparticles Designed for Future Enhanced Oil Recovery" presented at the Mediterranean Offshore Conference \& Exhibition (MOC 2016). Egypt, 19-21 April 2016.

19. Diagenode Innovating Epigentic Solutions.: "Sonication User Manual", Version 2.1., Belgium. 2009. 